\title{
Vegetation attributes drive the taxonomic richness and functional composition of beetles and spiders in mountainous urban green spaces
}

\author{
Frederick Gyasi Damptey ${ }^{1}$ - Bernard Fosu Frimpong ${ }^{2} \cdot$ Daniel Kwame Debrah $^{3} \cdot$ \\ Prince Pascal Agro ${ }^{4} \cdot$ Edward Debrah Wiafe $^{5}$ \\ ${ }^{1}$ Department of Ecology, Brandenburg University of Technology, Cottbus-Senftenberg, Germany \\ ${ }^{2}$ Department of Hydrology, Brandenburg University of Technology, Cottbus-Senftenberg, Germany \\ ${ }^{3}$ Forestry Research Institute of Ghana, Council for Scientific and Industrial Research, Kumasi, Ghana \\ ${ }^{4}$ Forest Services Division, Forestry Commission, Accra, Ghana \\ ${ }^{5}$ School of Natural and Environmental Sciences, University of Environment and Sustainable Development, Somanya, Ghana
}

Received: 27 May 2021 / Revised: 25 November 2021/Accepted: 4 December 2021/Published online: 5 January 2022

(C) The Author(s) 2022, corrected publication 2022

\begin{abstract}
Urban green spaces (UGS) enhance the quality of life in urban environments and serve as habitat corridors or refuge for organisms, including beetles and spiders. The attributes of UGS allow them to harbour species that offer essential ecosystem services. However, the ability of UGS to provide services is limited by the extent to which they have been altered anthropogenically. We described the taxonomic richness and functional composition of arthropods in a mountainous urban ecosystem of Ghana by focussing on the activity of both beetles and spiders at the family level. Two main land-use types (woodlands and built-up areas) were identified and characterised based on the presence or absence of certain vegetation attributes. Sixteen plots in each land-use type with sizes $20 \times 20 \mathrm{~m}$ were demarcated and fitted with four pitfall traps in each plot to sample continuously for eight weeks, the activity density of both beetles and spiders. Samples were sorted into families and functional groups (detritivores, fungivores, herbivores and predators). The taxonomic richness and activity density were both significantly higher in the woodlands than in the built-up areas. Similarly, all functional groups showed a higher affinity to the woodlands than the built-up areas. Habitat attributes defined by plant diversity and structural complexity were the underlying drivers explaining the differences in arthropod communities between the land-use types. Though the built-up areas seem degraded and open, the remaining small vegetation patches still support the activities of some taxa that should
\end{abstract}

Frederick Gyasi Damptey

FrederickGyasi.Damptey@b-tu.de merit the protection of such remnant vegetation in urban ecosystems.

Keywords Activity density - Arthropod community composition - Functional composition - Land-use change . Taxonomic richness $\cdot$ Mountainous urban ecosystem

\section{Introduction}

Urban green spaces (UGS) are ecosystems of significance, playing essential roles in biodiversity conservation as well as providing numerous ecosystem goods and services (Feltynowski and Kronenberg 2020; Kowarik et al. 2020; McPhearson et al. 2018). The characteristics of UGS (e.g., the degree of their naturalness, types of vegetation or diversity of plant species, types of fruits and flowers) allow them to harbour biodiversity (e.g., arthropods) that could offer essential services in the ecosystem and to society (Drillet et al. 2020; Duthie 2018). Such services include pollinating plants, decomposing organic materials, and regulating pest activities, amongst others (Damptey et al. 2021; Ramos et al. 2020). For instance, the predation activities of spiders regulate crop pests as a natural enemy, and the pollination role of bees and butterflies help plants to reproduce, while some beetles function as detritivorous, decomposing dead organic matter and contributing to nutrient cycling in ecosystems (Daniels et al. 2020; Nyffeler and Birkhofer 2017; Zanetti 2016).

The usefulness of UGS is hence seen by how they enhance the quality of life in urban environments, provide 
biodiversity, and offer habitat corridors or refuge for numerous species (Cameron et al. 2020; Planchuelo et al. 2019; Wang et al. 2019; Mata et al. 2017; Mensah et al. 2016). However, despite these contributions of UGS, they are under threat due to population growth (Vargas-Hernández and Zdunek-Wielgołaska 2021) coupled with other urban activities such as farming, and construction (Ives et al. 2016; Norton et al. 2016). Population growth hence has effects on land-use/land cover and biodiversity (Frimpong and Molkenthin 2021; Elmhagen et al. 2015). The conversion of land-use/land cover types (e.g. forest, agricultural lands, wetlands) to urban lands (e.g., built-up residential areas) is considered one of the major factors driving the changes in species diversity and subsequently affecting ecosystem productivity (Méndez-Rojas et al. 2021; Davis et al. 2019; Güneralp and Seto 2013; Seto et al. 2012). Hence, land-use/land cover change results in the reduction or extinction of native (and often endemic) species and sometimes an increase in non-native species (Mollot et al. 2017). It also impairs the habitats of some unique endemic species while creating alternative habitats for some unique species that can tolerate such urban conditions (Buczkowski and Richmond 2012).

Although seminal studies have confirmed that increasing land-use changes correlate strongly with a decline in biodiversity (Le Provost et al. 2020; Ahrne et al. 2009; Pauchard et al. 2006), there is also some evidence of some groups, especially certain insects or functional groups of arthropods peaking in terms of abundance in urban areas (Bang 2010; McIntyre 2000). Arthropod activity in urban areas primarily depends on vegetation and its attributes serving as habitat and food resources (Muller et al. 2014). These attributes (e.g., plant diversity, coarse wood debris, litter depth, etc.) offer food resources, serve as shelter, hibernation sites, and foraging sites for arthropods, as well as refuge from predation in urban ecosystems (Grodsky et al. 2018; Burks and Philpott 2017; Everett and Ruiz 1993).

Because of the synergetic relationship between arthropods and their environment, they have been used extensively as bio-indicators in assessing changes in the ecosystem induced by land-use/land cover change (Oliver et al. 2015; Hodkinson and Jackson 2005). For example, beetles and spiders are used as bio-indicators because of their short generation time, allowing them to respond quickly to changes in the urban environment (McIntyre 2000). Besides, they are abundant, occupy a broad range of niches and are present at many trophic levels (Borchard et al. 2014; McIntyre 2000). In addition, spiders play a role as predators reflecting changes in trophic structure in a human-altered ecosystem (Shochat et al. 2004), while beetles (e.g., Carabidae) echo ecological sustainability ecosystem health and reflect variations in natural conditions (Koivula, 2011). Besides, these groups are also sensitive to human-induced habitat disturbance (GómezCifuentes et al. 2017; Gardner et al. 2009).

An assemblage of communities depicts how species use resources or ecological components to perform their ecological functions (Choi et al. 2010; Blondel 2003). Some groups of species share similar morphological, physiological, and behavioural characteristics that allow them to be classified as functional groups because they perform similar functions in an ecosystem or process the same resources (Blondel 2003). These functional groups of arthropods often provide additional information on environmental changes because of their role in biological processes as predators, decomposers, pollinators, herbivores, etc. (Cardoso et al. 2013; Ulyshen and Hanula 2009).

We assessed how land-use changes affect the taxonomic richness and functional composition of spiders and beetles on a local scale in an urban setting characterised by green spaces (woodlands) and open habitat (built-up residential areas with little or no vegetation). We relied on grounddwelling spiders and beetles and evaluated the responses of these taxa to changes in land-use types. These taxa relate to the environment and play the roles of predators, pollinators, herbivores, and decomposers with specialised functions in different ecosystems (Buczkowski and Richmond 2012; Lee and Kwon 2015) as well as serving as an ideal system to assess the consequences of land-use change on a local scale (Christie et al. 2010).

\section{Materials and methods}

\subsection{Study area}

The impacts emanating from land-use changes on the taxonomic richness and functional composition of both spiders and beetles as well as their functional groups on a local scale were investigated in Akropong (latitude $5.955660^{\circ}$ and longitude $-0.096258^{\circ}$ ) on the Akuapim Hills of Ghana. Akropong is located in the Eastern Region of Ghana, about $58 \mathrm{~km}$ from Accra, the capital of Ghana (Fig. 1). The area is composed of a mixture of forest, shrub and other herbaceous vegetation and dominated by rocks of the Precambrian era, the Togo and Birimian series, with mountain and hilly terrain ranging between 381 and $488 \mathrm{~m}$ above sea level. Temperature ranges between 24 and $30{ }^{\circ} \mathrm{C}$ by the day, 13 and $24{ }^{\circ} \mathrm{C}$ by night with a bimodal annual rainfall pattern of $1270 \mathrm{~mm}$ (Owusu et al. 2015). The unique cold weather of the area and other geomorphological, edaphic and vegetation characteristics have created a micro-climatic range that serves as specific niches for diverse species (Wiafe 2014). Thus, the mountainous terrain of the area is characterised by a mosaic of different 


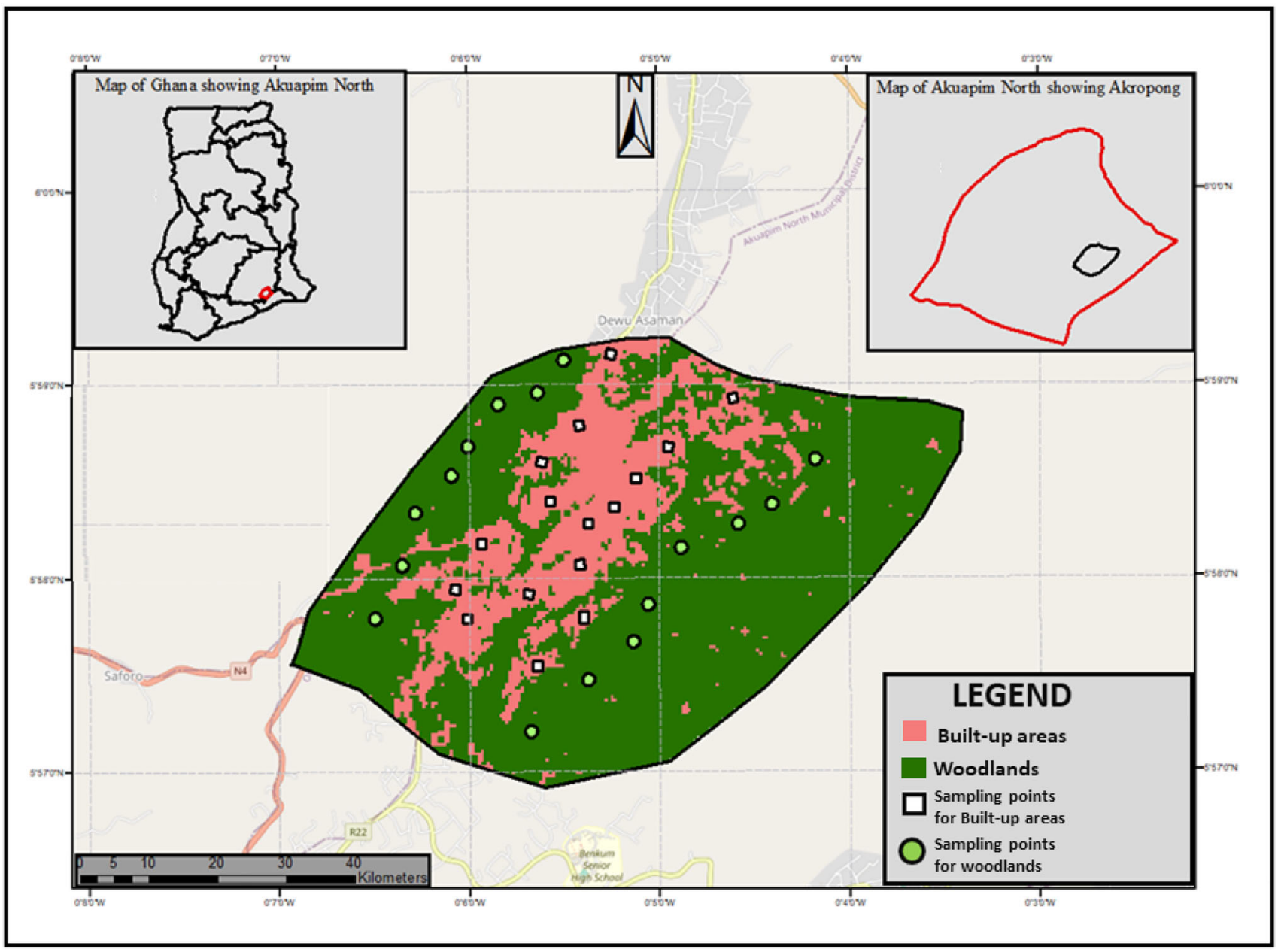

Fig. 1 Map of the study area showing the two land-use/land cover types (the built-up is classified in pink and the woodland in green). The square white square polygons are the sampling points for the built-up areas, and the round green polygons are the sampling points for the woodlands

ecosystems with different vegetation dominated by woodyherbaceous plant species of different lifeforms. The changing terrain profile of the area with diverse forms of ecosystems is significant for maintaining biodiversity and enhancing people's quality of life and health. That notwithstanding, these mountainous ecosystems are under threat from anthropogenic activities (e.g. farming, building, other construction works, etc.) and other biophysical factors.

\subsection{Sampling design}

Thirty-two (32) sampling plots with sizes $20 \times 20 \mathrm{~m}(16$ in areas covered by woodlands, 16 in built-up areas) that capture variations in land-use types were demarcated and sampled for beetles and spiders as well as habitat characteristics. Akropong township is endowed with about 24 managed green spaces. We randomly selected 16 out of the 24 green spaces that were less anthropogenically impacted and had enough tree population and vegetation cover. To obtain a standardised number of plots for comparison, we further selected 16 built-up areas with little or no vegetation cover at all. Plots were located at least $250 \mathrm{~m}$ apart to avoid spatial autocorrelation (Khanaposhtani et al. 2012). The study considered two main land-use/land cover types (woodland and residential-built-up areas). The woodland land-use/land cover type is defined by its heterogeneous tree cover on the Akuapim Hills. In contrast, the built-up areas are characterised by residential facilities, industrial, and commercial units.

\subsection{Sampling and sorting arthropods}

We relied on ground-dwelling spiders, beetles and their functional groups to investigate the effect of these anthropogenic changes on local biodiversity in a mountainous urban landscape of Ghana. We focussed on grounddwelling spiders and beetles because they are sensitive bioindicators reacting quickly to anthropogenically induced ecosystem changes (e.g., Beetles; Scarabaeinae), with their 
taxonomy and ecology well known (Carrion-Paladines et al. 2021; Latha and Sabu 2019; Nichols et al. 2007) and their diversity and versatility (e.g., spiders) playing an important role in terrestrial food webs as predators which are a major ecosystem function affected by disturbance (Potapov et al. 2020; Nyffeler and Birkhofer 2017; PreitoBenitez and Mendez 2011). Besides, these groups are diverse and well represented in a disturbed environment, are simple to sample and have some families being conspicuous and easy to identify (Arganaraz et al. 2020; Braga et al. 2013; Gerlach et al. 2013).

Ground-dwelling arthropods (beetles and spiders) were trapped using four pitfall traps in each 32 plots. Traps were filled with $50 \%$ propylene glycol mixed with water and roofed with disposable white plates to prevent dilution of the solvent by rains during the sampling period (Underwood and Quinn 2010). Trapping was carried out continuously for eight weeks in the dry season (February to March 2020), being emptied weekly (sampling effort $=4$ traps $\times 16$ plots $\times 8$ weeks $\times 2$ land-use types). Trapped samples were first sorted into taxonomic groups. The orders Coleoptera (beetles) and Araneae (spiders) were then sorted into various families, which were classified into four main functional groups (detritivores, fungivores, herbivores and predators) following Choi et al. (2010); Susilo et al. (2009); Lassau et al. (2005). Samples were preserved in 70\% ethanol and deposited at the Department of Environmental and Natural Resources Management Laboratory, Presbyterian University College, Ghana, for future projects.

\subsection{Sampling plant attributes}

All trees were counted within each demarcated plot, and their diameter at breast height ( $\mathrm{dbh}$ ) was measured with a diameter tape. Tree heights were measured using a Nikon Forestry pro II Laser Rangefinder (Nikon, USA). Vegetation height or layer and litter depth were measured with a graduated pole. For each plot, three measurements were taken and averaged to represent the vegetation height per plot. We measured deadwood diameter at the longitudinal midpoint with a diameter tape and length with a measuring tape. In addition, deadwood volume was calculated using Huber's formula (Husch et al. 2003). Finally, the percentage canopy openness, and vegetation cover of each plot were estimated (in percentages) based on images taken with a digital camera (brand: Sony Alpha a6000 Mirrorless Digital Camera with 16-500 mm lens) on mid-sunny days.

\subsection{Data analysis}

We estimated the taxonomic richness (based on family level) and activity density (active number of individuals caught per trap in a period of 8 weeks; Castro et al. 2014) of sampled arthropods per land-use type. We log-transformed $(\log (X+1))$ our dataset for further analysis due to its non-normal discrete distribution (Sokal and Rohlf 1987). Based on the log-transformed data, diversity indices (Pielou's evenness, Shannon, and Simpson; Pielou 1975; Simpson 1949; Shannon 1948) were estimated using the "Diverse" function in Primer vs 7. Statistically significant differences between the land-use types for diversity indices, taxonomic richness and activity density were evaluated with a one-factorial permutational analysis of variance (PERMANOVA) using Bray-Curtis similarity and an unrestricted permutation $(N=9999)$ of raw data with a type III (Partial) sum of squares (Clarke et al. 2014; Bray and Curtis 1957). Land-use type was used as a fixed factor with plot nested in land-use as a random factor.

To evaluate the magnitude of the differences in taxonomic composition between groups (woodlands and builtup areas), we estimated their effect sizes based on Hedges'd with bias-corrected 95\% bootstrap confidence intervals together with the resampling distribution from 5000 resamples (Ho et al. 2019).

A similarity percentage analysis (SIMPER) was used to estimate taxonomic contributions to the observed dissimilarities between land-use types based on a 70\% cut-off for lower taxonomic contribution (Clarke 1993). Finally, to determine the relative importance of predictor plant variables on arthropod community composition, the Linear Model (LM) and Variance partitioning based on Canonical correspondence analysis (CCA) were performed (Oksanen et al. 2011). All statistical analyses and visualisation were carried out with the Plymouth Routines in Multivariate Ecological Research (PRIMER vs 7, and the PERMANOVA add-on; Clarke and Gorley 2015), and the R statistical computing software version 2.15.3 (R Core Team 2019).

\section{Results}

A total of 5401 individual arthropods (beetles: 4019, spiders: 1382) were recorded across the two land-use types. The taxonomic richness and activity density were significantly higher in the woodlands than in the built-up areas. Except for Pielou's evenness which was not statistically significant between the two land-use types, both the Shannon and Simpson diversity indices were significantly higher in the woodlands than in the built-up areas. (Table 1).

The number of individual beetles was significantly higher in the woodlands (3267) than in the built-up areas (752), with the same trend recorded for taxonomic richness (Woodlands $=17$; Built-up $=14$; Table 2). Scarabaeidae 
Table 1 Diversity indices across the two land-use types. (Means and standard errors are given; $N$ per habitat $=16$ )

\begin{tabular}{lccccc}
\hline Indices & Woodlands & Built-up & $p$-value \\
\hline Taxonomic richness (S) & 32 & 26 & $\mathbf{0 . 0 0 1}$ \\
No. of individuals (N) & 4074 & 1327 & $\mathbf{0 . 0 0 1}$ \\
Activity density (A_D) & \multicolumn{2}{c}{34.605} & 18.467 & $\mathbf{0 . 0 0 1}$ \\
\hline & Mean & SE & Mean & SE & \\
\hline Pielou's evenness (J) & 0.939 & 0.00 & 0.943 & 0.00 & 0.438 \\
Shannon (H'loge) & 2.699 & 0.05 & 2.220 & 0.06 & $\mathbf{0 . 0 0 1}$ \\
Simpson (1-Lambda) & 0.950 & 0.00 & 0.929 & 0.01 & $\mathbf{0 . 0 0 2}$
\end{tabular}

Differences in indices for the land-use types were tested by applying One-Way ANOVA $(p<0.05)$. Significant pairs are in bold

was the most abundant family in both land-use types (Woodlands $=975$; Built-up $=322$ ). Beetle family composition differed significantly between the two land-use types $\left(F_{1,30}=43.12 ; p=0.001\right.$; Table 3$)$. Hydrophilidae, Scaphidiidae, Staphylinidae, and Trogossilidae were utterly absent in built-up areas, while only Trogidae was absent in the Woodlands.

Spider family composition also differed significantly between the two land-use types $\left(F_{1,30}=6.50 ; p=0.001\right.$; Table 3), with Lycosidae being the most dominant family
Table 3 Taxonomic composition across the two land-use types

\begin{tabular}{lcccll}
\hline Taxa & Factor & $d f$ & Pseudo-F & $P$ (perm) & Unique perms \\
\hline Beetles & Site & 1 & 58.468 & 0.001 & 9948 \\
Spiders & Site & 1 & 6.503 & 0.001 & 9955 \\
\multicolumn{2}{l}{ Functional groups } & & & & \\
Detritivores & Site & 1 & 97.010 & 0.001 & 9918 \\
Fungivores & Site & 1 & 94.918 & 0.001 & 9803 \\
Herbivores & Site & 1 & 36.630 & 0.001 & 9926 \\
Predators & Site & 1 & 55.914 & 0.001 & 9897 \\
\hline
\end{tabular}

Differences in taxa for the land-use types were tested by applying One-Way ANOVA $(p<0.05)$

across the two land-use types (Woodland $=477$; Builtup $=355$; Table 2). Individual spiders were higher in woodland plots (807) than in built-up areas (573). The same holds for their taxonomic family richness (Woodland = 16; Built-up =13). Members from the spider families Idiopidae, Migidae, and Theraphosidae were completely absent in the built-up areas, while only Palpimanidae was absent in the woodland plots.

The activity of Trogidae and Curculionidae characterised the built-up areas, while the woodland plots were shaped by Carabidae, Endomychidae, Cetoniidae,

Table 2 Number of individual families across land-use types. Differences in land-use types for each group (spiders, beetles) were tested by applying One-Way ANOVA $(p<0.05)$

\begin{tabular}{|c|c|c|c|c|c|c|c|}
\hline Beetles & Wood-lands & Built-up & ANOVA & Spiders & Wood-lands & Built-up & ANOVA \\
\hline Bruchidae & 1 & 1 & 1.000 & Barychelidae & 10 & 2 & 0.289 \\
\hline Carabidae & 555 & 270 & 0.001 & Corinnidae & 31 & 52 & 0.138 \\
\hline Cetoniidae & 51 & 3 & 0.001 & Ctenidae & 82 & 11 & 0.001 \\
\hline Curculionidae & 29 & 8 & 0.004 & Cyrtaucheniidae & 25 & 9 & 0.062 \\
\hline Endomychide & 1 & 4 & 0.243 & Gnaphosidae & 5 & 6 & 0.817 \\
\hline Elateridae & 8 & 9 & 0.850 & Idiopidae & 4 & 0 & 0.033 \\
\hline Erotylidae & 198 & 9 & 0.001 & Liocranidae & 1 & 3 & 0.532 \\
\hline Histeridae & 29 & 87 & 0.009 & Lycosidae & 477 & 355 & 0.069 \\
\hline Hydrophilidae & 209 & 25 & 0.001 & Migidae & 33 & 0 & 0.008 \\
\hline Nitidulidae & 894 & 7 & 0.001 & Oxyopidae & 3 & 5 & 0.431 \\
\hline Pselaphidae & 23 & 2 & 0.001 & Palpimanidae & 0 & 4 & 0.034 \\
\hline Scarabaeidae & 975 & 322 & 0.001 & Salticidae & 61 & 23 & 0.077 \\
\hline Scaphidiidae & 3 & 0 & 0.073 & Teteragnathidae & 2 & 1 & 0.559 \\
\hline Scydmaenidae & 8 & 1 & 0.005 & Theraphosdae & 2 & 0 & 0.154 \\
\hline Staphylinidae & 41 & 0 & 0.001 & Thomisidae & 4 & 2 & 0.381 \\
\hline Tenebrionidae & 196 & 4 & 0.001 & Zodariidae & 67 & 122 & 0.073 \\
\hline Trogossilidae & 5 & 0 & 0.014 & & & & \\
\hline No. of individuals & 3226 & 752 & & No. of individuals & 807 & 575 & \\
\hline Taxonomic richness & 17 & 14 & & Taxonomic richness & 16 & 13 & \\
\hline
\end{tabular}

Significant pairs are in bold 
Hydrophilidae, Elateridae, Erotylidae, Curculionidae etc. There was no effect of land-use type on either Bruchidae or Elateridae (Fig. 2a).

The distinction between the two land-use types in terms of beetle family composition was confirmed by a One-Way ANOSIM $(R=0.975, p=0.01)$. An average dissimilarity (based on SIMPER) of about $70 \%$ is confirmed between the two land-use types, with 4 out of 18 families contributing approximately $75 \%$ to the above dissimilarity. Nitidulidae is the most discriminating beetle family, contributing about $29 \%$ to the average dissimilarity between land-use types. Higher activities of Nitudilidae, Scarabaeidae, Carabidae and Hydrophilidae, were observed in the woodland plots than in the built-up areas. Hydrophilidae was utterly absent in the built-up areas (Table 4).

Corinnidae, Liocranidae, Oxyopidae, Palpimanidae and Zodariidae characterised the built-up areas for spider family composition, while Ctenidae, Cyrtaucheniidae,
Fig. 2 Mean effect size (Hedges'd) and bias-corrected 95\%- bootstrap confidence intervals for differences in the land-use types for each a beetle, b spider family
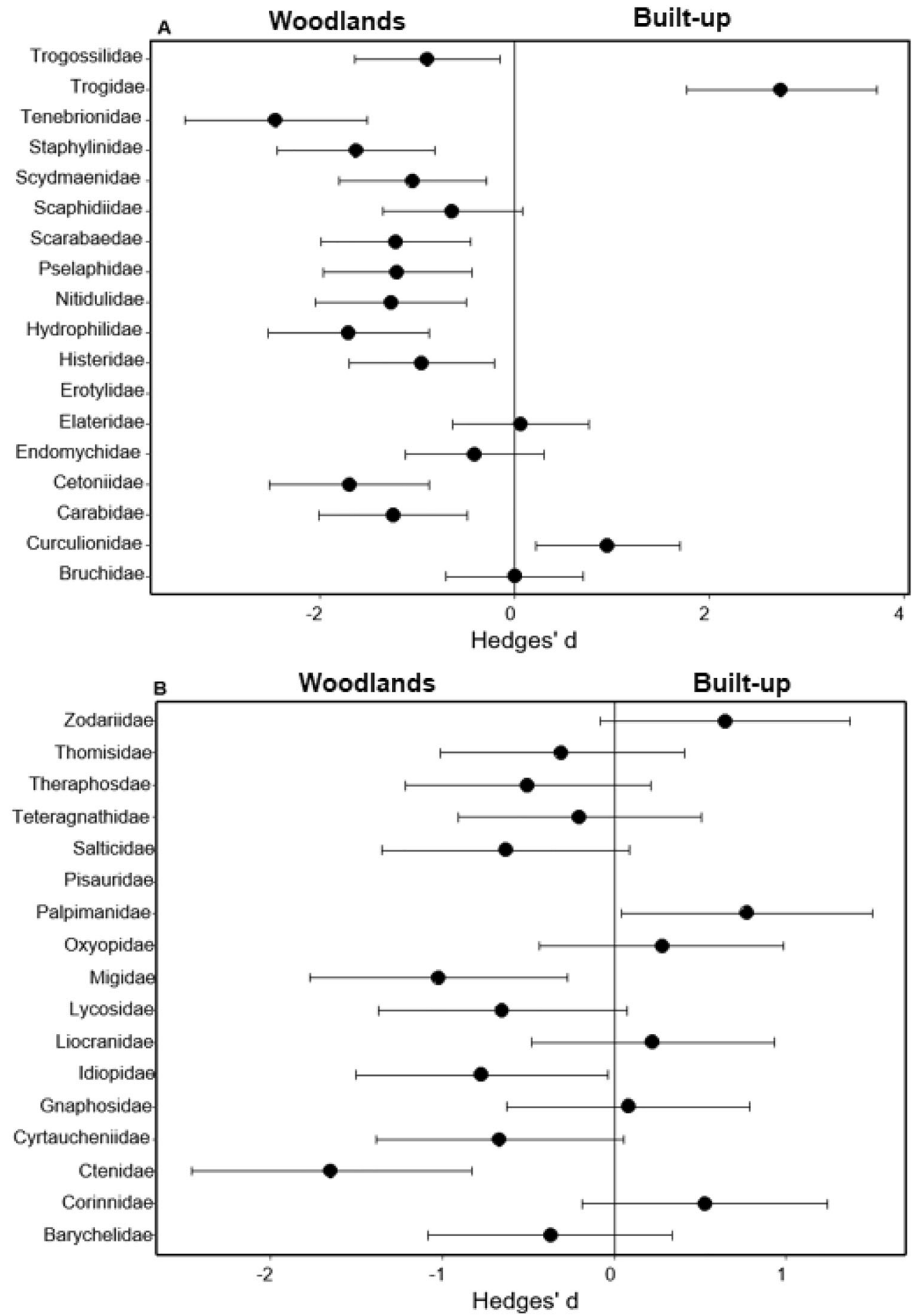
Table 4 Comparative contribution of the individual beetle and spider families (based on SIMPER) to the distinctions between the land-use types

\begin{tabular}{lllllllrrr}
\hline $\begin{array}{l}\text { Beetles } \\
\text { family }\end{array}$ & $\begin{array}{l}\text { Wood-land Av. } \\
\mathrm{Ab}\end{array}$ & $\begin{array}{l}\text { Built-up Av. } \\
\mathrm{Ab}\end{array}$ & Contrib\% & $\begin{array}{l}\text { Cum. } \\
\%\end{array}$ & $\begin{array}{l}\text { Spiders } \\
\text { family }\end{array}$ & \multicolumn{2}{l}{$\begin{array}{l}\text { Wood-land Av. } \\
\mathrm{Ab}\end{array}$} & $\begin{array}{l}\text { Built-up Av. } \\
\mathrm{Ab}\end{array}$ & $\begin{array}{l}\text { Contrib\% } \\
\text { Cum.\% }\end{array}$ \\
\hline Nitidulidae & 55.88 & 0.44 & 28.62 & 28.62 & Lycosidae & 29.81 & 20.94 & 42.59 & 42.59 \\
Scarabaeidae & 60.94 & 20.13 & 25.37 & 54.00 & Zodariidae & 4.19 & 7.63 & 17.94 & 60.53 \\
Carabidae & 34.69 & 16.88 & 12.86 & 66.86 & Ctenidae & 5.13 & 0.69 & 10.39 & 70.92 \\
Hydrophilidae & 13.06 & 0.00 & 7.99 & 74.85 & & & & \\
\hline
\end{tabular}

The resemblance is based on Bray-Curtis similarity and $70 \%$ cut-off for low contribution. (Av. Ab. = Average abundance, Contrib $\%=$ contribution percentage, Cum $\%=$ Cumulative percentage)

Barychelidae, Idiopidae, Ctenidae, Salticidae, amongst others, shaped the woodland plots (Fig. 2b). The distinction between the two land-use types in terms of spider family composition was confirmed by a One-Way ANOSIM $(R=0.325, p=0.04)$. An average dissimilarity (based on SIMPER) of about $48 \%$ was confirmed between the two land-use types, with 3 out of 17 families contributing approximately $71 \%$ to the above dissimilarity. Lycosidae contributed about $43 \%$ to the above dissimilarity. A higher abundance of Lycosidae and Ctenidae was recorded in the woodland plots than in the built-up areas (Table 4).

The habitat attribute variations defined by plants and vegetation properties in each land-use type (Table 5) could explain the differences in arthropod taxa composition between the two land-use types. Except for tree canopy openness which was significantly higher in the built-up areas, all other habitat attributes were significantly higher in the woodland plots (Table 5).

A significant relationship was observed between arthropod taxa (beetles and spider) and habitat variables $(p=0.008)$. The first principal axis explained $67 \%$ of the variation $(p=0.005)$, while the second axis also explained $16 \%$ of the total variation $(p=0.197)$. The CCA triplot showed that Palpimalidae, Liocrinidae and Trogossilidae were closely associated with canopy openness in the builtup areas. Erotylidae, Nitidulidae and Idioidae were also closely associated with tree height, and Staphylinidae was also influenced by tree size $(d b h)$. Theraphosidae, Scarabaeidae, Hydrophilidae and Trogossilidae were also associated with tree abundance, litter depth, and deadwood volume (Fig. 3). Families such as Scarabaeidae, Ctoniidae, Histeridae, Curculionidae, Lycosidae, Hydrophilidae, and Cteniidae concentrated at the centre of the triplot suggest that their abundance may be associated with a combination of habitat attributes instead of just a single habitat attribute.

All four functional groups differed significantly between the two land-use types, with all groups exhibiting significantly higher activity density in the woodland plots than built-up areas (Fig. 4).

\section{Discussion}

\subsection{Differences in taxonomic richness and activity density of beetles and spiders across land-use types}

The taxonomic richness and activity density were significantly higher in the woodlands than in the residential land-
Table 5 Habitat attributes (mean values and SE) of the two land-use types

\begin{tabular}{|c|c|c|c|c|c|}
\hline \multirow[t]{2}{*}{ Habitat attributes } & \multicolumn{2}{|l|}{ Built-up } & \multicolumn{2}{|c|}{ Woodland } & \multirow[t]{2}{*}{$p$ Value } \\
\hline & Mean & SE & Mean & SE & \\
\hline Tree abundance & 2 & 0.44 & 17 & 1.99 & 0.001 \\
\hline Tree diameter $(\mathrm{cm})$ & 7.721 & 1.38 & 16.590 & 1.34 & 0.001 \\
\hline Tree height $(\mathrm{m})$ & 5.875 & 1.05 & 9.250 & 0.41 & 0.005 \\
\hline Tree canopy openness (\%) & 89.563 & 2.42 & 20.250 & 1.36 & 0.001 \\
\hline Vegetation cover $(\%)$ & 18.688 & 3.62 & 75.813 & 1.80 & 0.001 \\
\hline Vegetation height (m) & 0.481 & 0.10 & 1.425 & 0.05 & 0.001 \\
\hline Litter depth (m) & 0.023 & 0.01 & 0.304 & 0.03 & 0.001 \\
\hline Deadwood volume $(\mathrm{Mg} / \mathrm{ha})$ & 1.259 & 0.31 & 8.633 & 0.54 & 0.001 \\
\hline
\end{tabular}

Differences in attributes for the land-use types were tested by applying One-Way ANOVA $(p<0.05)$ 


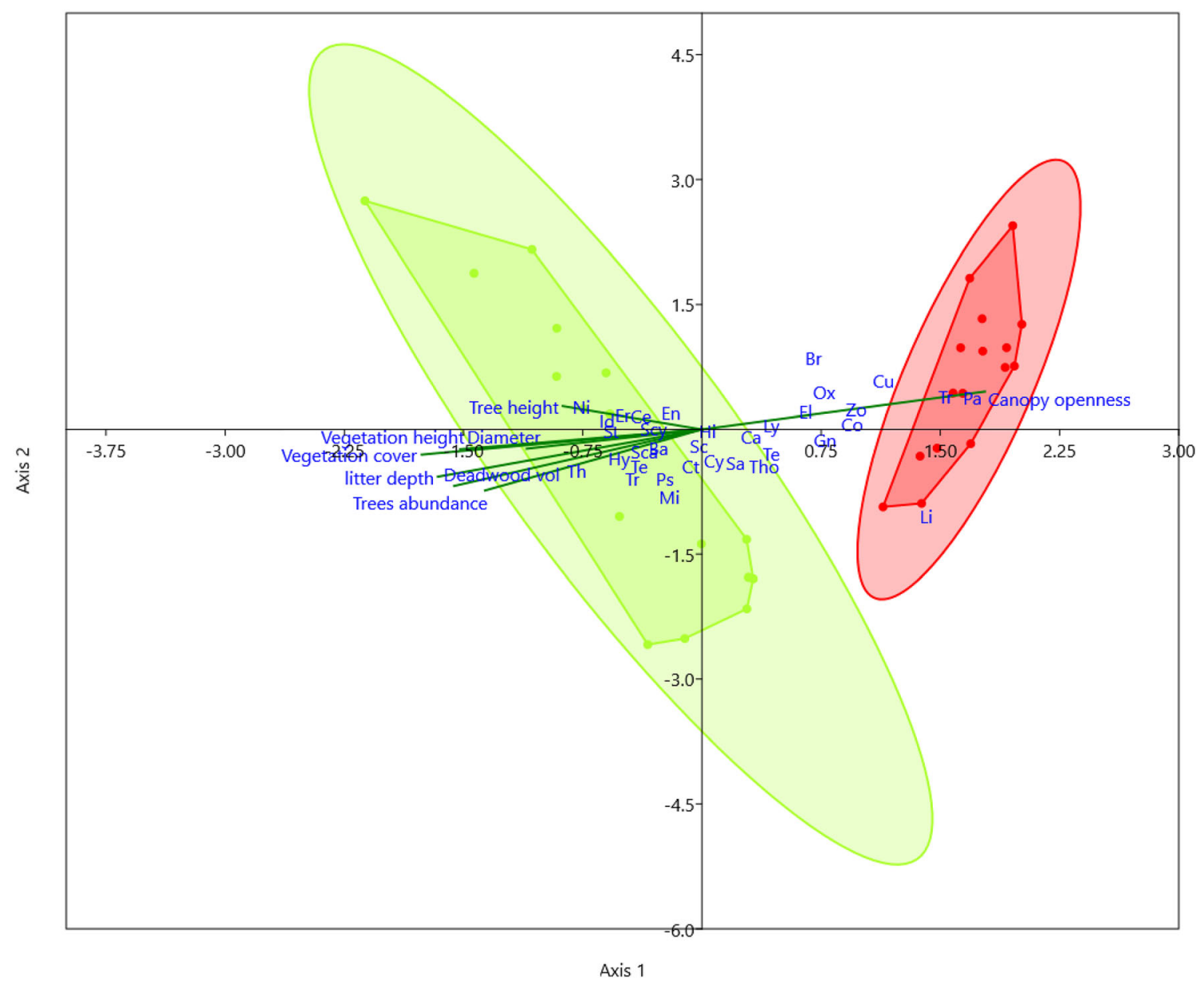

Fig. 3 CCA of 35 arthropod taxa across the two land-use types (Woodland in green, Built-up areas in red). Abbreviations: BaBarychelidae, Co- Corinnidae, Ct- Ctenidae, Cy- Cyrtaucheniidae, Gn- Gnaphosidae, Id- Idiopidae, Li- Liocranidae, Ly- Lycosidae, MiMigidae, Ox- Oxyopidae, Pa- Palpimanidae, Pi- Pisauridae, SaSalticidae, Te- Teteragnathidae, Th- Theraphosdae, Tho- Thomisidae,

use type. Different groups reacted differently based on the magnitude of changes in land-use types (Fenoglio et al. 2020). These differences could be due to the influential roles of plant attributes favouring the activity of both beetles and spiders in the woodlands. For example, a more abundant tree species, greater vegetation cover, higher deadwood volume, and the different strata defined by vegetation and tree height might have created a wider potential diversity of available ecological niches (Keroumi et al. 2012). These ecological niches might have created an appropriate habitat and offered possible food resources (e.g., leaves, fruits and seeds) for most taxa's existence, survival, and activity in the woodland plots compared to the built-up areas. Hence, diverse trees serve as "keystone structures", providing habitats for beetles and spiders (Schuldt et al. 2019; Schowalter 2017; Sebek et al. 2016). Our results confirm that arthropod taxonomic richness and
Zo- Zodariidae, Br- Bruchidae, Ca- Carabidae, Ce- Cetoniidae, $\mathrm{Cu}$ Curculionidae, En- Endomychide, El- Elateridae, Er- Erotylidae, HiHisteridae, Hy- Hydrophilidae, Ni- Nitidulidae, Ps- Pselaphidae, ScScarabaedae, Sca- Scaphidiidae, Scy- Scydmaenidae, St- Staphylinidae, Ten- Tenebrionidae, Tr- Trogossilidae

activity increase with vegetation complexity defined by its diversity and structure (Mata et al. 2020; Wenninger and Inouye 2008; Lassau et al. 2005). In a similar study, beetle activity increased with vegetation diversity (Jouveau et al. 2020), while vegetation structure complexity enhanced spider activity (Štokmane and Spungis 2016).

Moreover, the activity of beetles correlated positively with all measured habitat characteristics, in agreement with previous studies highlighting the positive roles of habitat attributes on beetle diversity. For instance, deadwood volume has been discussed extensively to increase beetle (saproxylic) activity (Ekström et al. 2021; Haeler et al. 2021; Schiegg 2000), offer important microhabitat (Dufour-Pelletier et al. 2020; Bače et al. 2019; Seibold and Thorn 2018), provide refuge from predation (Seibold 2015) and offer food resources (Parisi et al. 2018). 
Fig. 4 Activity density of arthropod functional groups in woodlands and built-up areas (a: Detritivores, b: Fungivores, c: Herbivores and $\mathbf{d}$ : Predators)

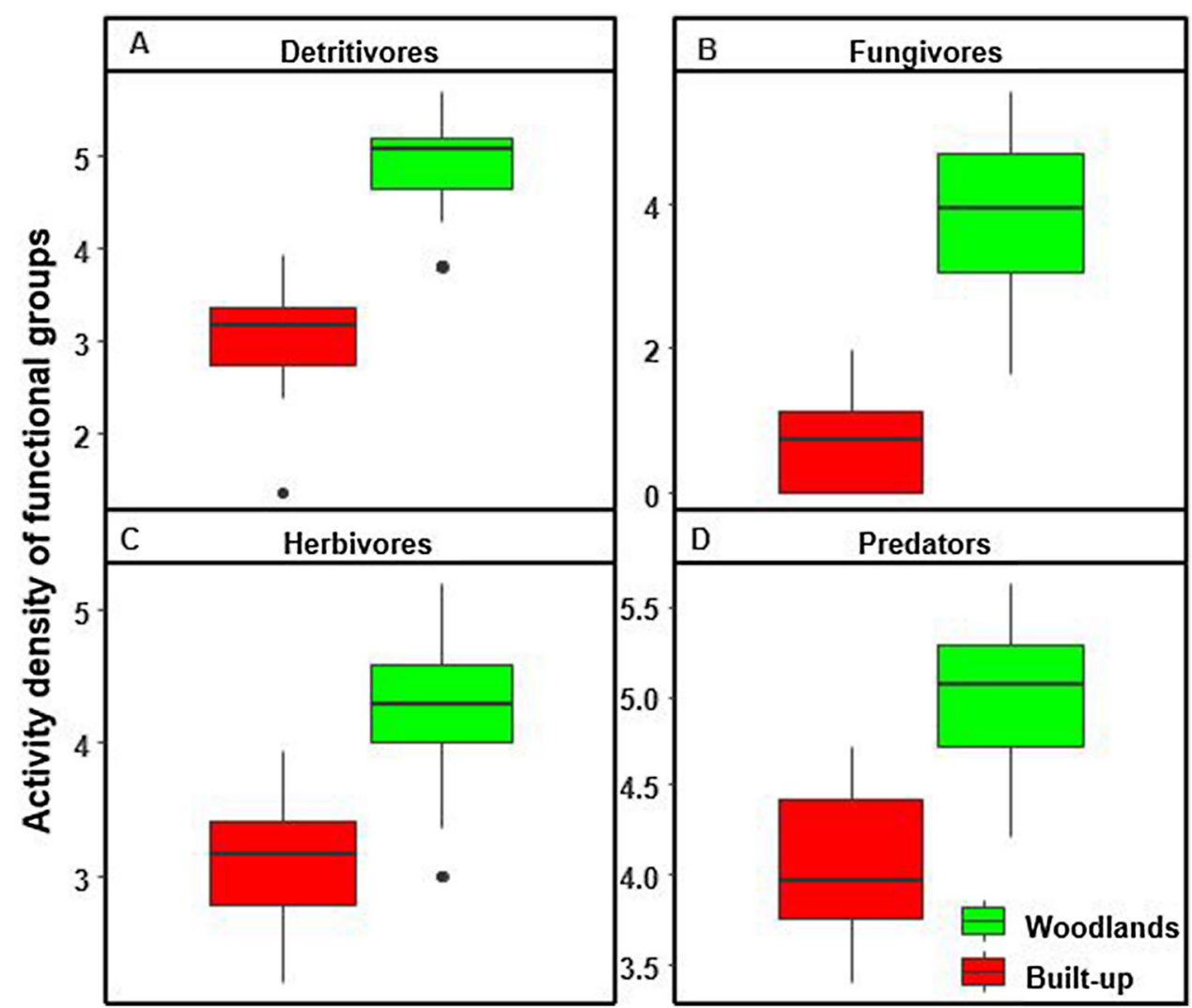

\subsection{Characteristic taxa of the different land-use types}

Most beetle taxa showed a stronger affinity for woodlands, which could be related to the availability of food and habitat resources offered by such woodlands. Most species of Carabidae are usually polyphagous and predacious on other arthropods, which prefer habitats characterised by diverse tree species (Bergmann et al. 2012). Such habitats usually harbour other arthropods, which are preyed on by Carabidae (Ebeling et al. 2018). The higher activity of Endomychidae in the woodlands also confirms their positive association with habitat attributes such as deadwood volume because they prefer decaying wood or fungal spores (Leschen 1993). Most species within Endomychidae exploit diverse fungi and the microhabitats they provide (Majka 2007). Histeridae were also dominant in the woodlands because they are generalist predators with a wide range of habitats but reduce activity in open and degraded ecosystems (Cajaiba 2017). Lassau et al. (2005) affirmed the role of habitat complexity in shaping beetle families such as Staphylinidae and Carabidae. Complex habitats usually provide diverse conditions for organisms because of the variety of microhabitats and trees that characterise such habitats (Khanaposhtani et al. 2012).
The activities of Bruchidae and Elateridae was neutral and showed no preference for any of the two land-use types. Trogidae and Curculionidae were the only two beetle families that showed a higher affinity to the built-up areas. We could, in this case, not assign any tangible explanation to this trend; however, we could only speculate that other factors aside from vegetation attributes (e.g. exposure to the sun leading to the dryness of the area or bare ground providing exceptional support) contributed to the dominance of these two families of beetles in the built-up areas.

A comparison between the spider and beetle groups revealed that they both reacted differently to habitat complexity. A more significant proportion of their taxa showed a preference for either the woodland or the built-up areas, confirming their strong association with habitat characteristics (Entling et al. 2007). The variation in land-use types driven by environmental conditions associated with vegetation attributes could explain the differences in spider and beetle communities between the two land-use types (Delgado de la flor et al. 2020; Štokmane and Spungis 2016).

\subsection{Effect of habitat characteristics on arthropod functional groups}

All four functional groups (detritivores, fungivores, herbivores and predators) were significantly higher in the 
woodlands than in the built-up areas. This trend may have been mediated by the habitat characteristics of the two land-use types. Our results affirmed that functional group activity becomes more pronounced when plant diversity increases with structural complexity (Sattler et al. 2010). Accordingly, a complex habitat structure may have modified the niche space and offered resources for the activity of the various functional group's (Staab and Schuldt 2020).

The built-up of ground litter and deadwood volume within the woodland areas might have benefited the detritivores. This perhaps could be attributed to their saproxylic nature, thus living and feeding on decayed wood and other decomposing plant parts (Mestre et al. 2018; Parisi et al. 2018; Wende et al. 2017). Higher predator activity in woodlands could be a response of these groups to more diverse vegetation, often coupled with higher prey availability (Diehl et al. 2013). In a similar study, a diverse and complex vegetation structure of woodlands (forests) offered alternative habitats and prey, subsequently increasing predatory organism numbers (Damptey et al. 2021). In addition, this diverse vegetation might have also provided refuge for predators (Barnes et al. 2020). Herbivores activity correlated significantly with plant attributes in the woodlands. For instance, herbivores activity increased with increasing tree diversity of the woodlands. Hence, diverse tree habitats support a greater range of feeding demands by herbivores (O'Brien et al. 2017). In addition, these diverse trees offer a variety of diets, which subsequently improve herbivores fitness, leading to their higher activity (Coley and Barone 1996).

\section{Conclusion}

Our results revealed that the built-up areas were open and degraded with little capacity to support most beetle and spider activities. However, their small remnant vegetation provided the necessary habitat and feeding resources for some specialised groups, including Trogidae, Curculionidae, Zodariidae, Palpimanidae, Oxyopidae and Corrinidae. Habitat characteristics played an important role in explaining the variations in arthropod community composition between the two land-use types. Plant diversity and vegetation complexity offered the strongest explanatory power to the observed arthropod community differences. This then points to the need to continuously conserve such remnant vegetation in urban ecosystems to support some taxonomic groups of ecological value.

The results of this study are relevant for urban planners and managers in incorporating green spaces in urban landscape designs to save the few urban arthropod communities that are useful in ecosystem service provision.
We only had a small sampling size and did not consider the seasonal effects on arthropods across multiple land-use types other than woodland and built-up areas. Therefore, we recommend that future studies focus on unraveling seasonal factors and their interactions with different landuse types to shape the arthropod community in an urban setting. We also recommend that urban planners and managers consider planting multipurpose tree species in built-up areas to provide shade, habitat, and food resources for arthropods, birds, and other small mammals. Finally, urban planners could enhance the habitat quality of remnant vegetation by collaboratively engaging community members and other relevant stakeholders in urban greening projects.

Acknowledgements Authors are grateful to the Centre for International Migration and Development (CIM)—Deutsche Gesellschaft für Internationale Zusammenarbeit (GIZ) $\mathrm{GmbH}$ for funding the lead researcher's (FGD) Diaspora Expert Mission to the Presbyterian University College, Ghana-Akuapem Campus. We are also grateful to Presbyterian University College for hosting FGD and providing a befitting laboratory for this project. We would also like to thank the reviewers and the editor for their comments on a previous version of this manuscript. Special thanks to Forest Aid Ghana and EcoCare Ghana for resourcing us logistically. Lovina Kwapong Asanti, Gerald Afari Antwi Boasiako, Eric Amponsah, Gloria Agyekum (all of Presbyterian University College, Akuapem Campus) and Richard Quarshie (Presbyterian Senior High School - Bechem) helped with the field and laboratory work.

Author's contributions All authors contributed to the study's conception and design. Material preparation, data collection and analysis were performed by FGD, BFF, DKD, PPA and EDW. FGD wrote the first draft of the manuscript and all authors commented on previous versions of the manuscript. All authors read and approved the final manuscript.

Funding Open Access funding enabled and organized by Projekt DEAL.

Data availability statement The data that support the findings of this study are openly available in figshare https://doi.org/10.6084/m9.fig share.16556211.v1.

\section{Declaration}

Conflict of interest On behalf of all authors, the corresponding author states that there is no conflict of interest.

Open Access This article is licensed under a Creative Commons Attribution 4.0 International License, which permits use, sharing, adaptation, distribution and reproduction in any medium or format, as long as you give appropriate credit to the original author(s) and the source, provide a link to the Creative Commons licence, and indicate if changes were made. The images or other third party material in this article are included in the article's Creative Commons licence, unless indicated otherwise in a credit line to the material. If material is not included in the article's Creative Commons licence and your intended use is not permitted by statutory regulation or exceeds the permitted use, you will need to obtain permission directly from the copyright 
holder. To view a copy of this licence, visit http://creativecommons. org/licenses/by/4.0/.

\section{References}

Ahrne K, Bengtsson J, Elmqvist T (2009) Bumble bees (Bombus spp) along a gradient of increasing urbanisation. PLoS ONE 4(5):e5574

Argañaraz CI, Rubio GD, Rubio M, Castellarini F (2020) Grounddwelling spiders in agroecosystems of the Dry Chaco: a rapid assessment of community shifts in response to land-use changes. Biodiversity 21(3):125-135

Bače R, Svoboda M, Vítková L (2019) Deadwood management in production forests. Management guidelines for forest managers in Central European temperate forests, (s 31). Department of Forest Ecology, Faculty of Forestry and Wood Sciences, Czech University of Life, Prague

Bang C Jr (2010) Effects of urbanisation on arthropod diversity, community structure and trophic dynamics. Arizona State University, Arizona

Barnes AD, Scherber C, Brose U, Borer ET, Ebeling A, Gauzens B, Eisenhauer N (2020) Biodiversity enhances the multitrophic control of arthropod herbivores. Sci Adv 6(45):eabb6603

Bergmann DJ, Brandenburg D, Petit S, Gabel M (2012) Habitat preferences of ground beetle (Coleoptera: Carabidae) species in the northern Black Hills of South Dakota. Environ Entomol 41(5):1069-1076

Blondel J (2003) Guilds or functional groups: does it matter? Oikos 100(2):223-231

Borchard F, Buchholz S, Helbing F, Fartmann T (2014) Carabid beetles and spiders as bioindicators for the evaluation of montane heathland restoration on former spruce forests. Biol Cons 178:185-192

Braga RF, Korasaki V, Andresen E, Louzada J (2013) Dung beetle community and functions along a habitat-disturbance gradient in the Amazon: a rapid assessment of ecological functions associated to biodiversity. PLoS ONE 8(2):e57786

Bray JR, Curtis JT (1957) An ordination of the upland forest communities of southern Wisconsin. Ecol Monogr 27(4):326-349

Buczkowski G, Richmond DS (2012) The effect of urbanisation on ant abundance and diversity: a temporal examination of factors affecting biodiversity. PLoS ONE 7(8):e41729

Burks JM, Philpott SM (2017) Local and landscape drivers of parasitoid abundance, richness, and composition in urban gardens. Environ Entomol 46(2):201-209

Cajaiba RL, Périco E, Silva WB, Santos M (2017) Seasonal patterns in the diversity of Histerid beetles (Histeridae) are ecosystem specific? A case in Para State, Northern Brazil. Appl Ecol Environ Res 15(4):1227-1237

Cameron RW, Brindley P, Mears M, McEwan K, Ferguson F, Sheffield D, Richardson M (2020) Where the wild things are! Do urban green spaces with greater avian biodiversity promote more positive emotions in humans? Urban Ecosyst 23(2):301-317

Cardoso EJBN, Vasconcellos RLF, Bini D, Miyauchi MYH, Santos CAD, Alves PRL, Nogueira MA (2013) Soil health: looking for suitable indicators. What should be considered to assess the effects of use and management on soil health? Sci Agric 70(4):274-289

Carrión-Paladines V, Fries A, Muñoz A, Castillo E, García-Ruiz R, Marín-Armijos D (2021) Effects of land-use change on the community structure of the dung beetle (Scarabaeinae) in an altered ecosystem in Southern Ecuador. Insects 12(4):306
Castro AV, Porrini DP, Cicchino AC (2014) Annual Activity Density of groundbeetles (Coleoptera: Carabidae) of a Celtis ehrenbergiana (Rosales: Celtidaceae) Forest of Buenos Aires Province, Argentina. J Insect Sci 14(1)

Choi WI, Choi KS, Lyu DP, Lee JS, Lim J, Lee S, Park YS (2010) Seasonal changes of functional groups in coleopteran communities in pine forests. Biodivers Conserv 19(8):2291-2305

Christie FJ, Cassis G, Hochuli DF (2010) Urbanisation affects the trophic structure of arboreal arthropod communities. Urban Ecosyst 13(2):169-180

Clarke KR, Gorley RN, Somerfield PJ, Warwick RM (2014) Change in marine communities: an approach to statistical analysis and interpretation, 3nd edn. PRIMER-E, Plymouth

Clarke KR, Gorley RN (2015) Getting started with PRIMER v7. PRIMER-E, Plymouth, Plymouth Marine Laboratory, 20

Clarke KR (1993) Non-parametric multivariate analyses of changes in community structure. Aust J Ecol 18(1):117-143

Coley PD, Barone JA (1996) Herbivores and plant defenses in tropical forests. Annu Rev Ecol Syst 27(1):305-335

Damptey FG, de la Riva EG, Birkhofer K (2021) Trade-offs and synergies between food and fodder production and other ecosystem services in an actively restored forest, natural forest and an agroforestry system in Ghana. Front for Global Chang $4: 47$

Daniels B, Jedamski J, Ottermanns R, Ross-Nickoll M (2020) A "plan bee" for cities: pollinator diversity and plant-pollinator interactions in urban green spaces. PLoS ONE 15(7):e0235492

Davis KF, Dalin C, DeFries R, Galloway JN, Leach AM, Mueller ND (2019) Sustainable pathways for meeting future food demand. In: Ferranti P, Berry EM, Anderson JR (eds) Encyclopedia of food security and sustainability, vol 3

Delgado de la Flor YA, Perry KI, Turo KJ, Parker DM, Thompson JL, Gardiner MM (2020) Local and landscape-scale environmental filters drive the functional diversity and taxonomic composition of spiders across urban greenspaces. J Appl Ecol 57(8):1570-1580

Diehl E, Sereda E, Wolters V, Birkhofer K (2013) Effects of predator specialisation, host plant and climate on biological control of aphids by natural enemies: a meta-analysis. J Appl Ecol 50(1):262-270

Drillet Z, Fung TK, Leong RAT, Sachidhanandam U, Edwards P, Richards D (2020) Urban vegetation types are not perceived equally in providing ecosystem services and disservices. Sustainability 12(5):2076

Dufour-Pelletier S, Tremblay AJ, Hébert C, Lachat T, Ibarzabal J (2020) Testing the effect of snag and cavity supply on deadwood-associated species in a managed boreal forest. Forests 11(4):424

Duthie T (2018) An assessment of ecosystem services and disservices in urban community gardens in Berlin (Germany) and Cape Town (South Africa). Doctoral dissertation, University of Leipzig, Leipzig, Germany. Retrieved from https://core.ac.uk/ download/pdf/226136519.pdf

Ebeling A, Hines J, Hertzog LR, Lange M, Meyer ST, Simons NK, Weisser WW (2018) Plant diversity effects on arthropods and arthropod-dependent ecosystem functions in a biodiversity experiment. Basic Appl Ecol 26:50-63

Entling W, Schmidt MH, Bacher S, Brandl R, Nentwig W (2007) Niche properties of Central European spiders: shading, moisture and the evolution of the habitat niche. Glob Ecol Biogeogr 16(4):440-448

Ekström AL, Bergmark P, Hekkala AM (2021) Can multifunctional forest landscapes sustain a high diversity of saproxylic beetles? For Ecol Manag 490:119107

Elmhagen B, Destouni G, Angerbjörn A, Borgström S, Boyd E, Cousins SA et al (2015) Interacting effects of change in climate, 
human population, land use, and water use on biodiversity and ecosystem services. Ecol Soc 20(1)

Everett RA, Ruiz GM (1993) Coarse woody debris as a refuge from predation in aquatic communities. Oecologia 93(4):475-486

Feltynowski M, Kronenberg J (2020) Urban green spaces-an underestimated resource in third-tier towns in Poland. Land 9(11):453

Fenoglio MS, Rossetti MR, Videla M (2020) Negative effects of urbanisation on terrestrial arthropod communities: a metaanalysis. Glob Ecol Biogeogr 29(8):1412-1429

Frimpong BF, Molkenthin F (2021) Tracking urban expansion using random forests for the classification of landsat imagery (1986-2015) and predicting urban/built-up areas for 2025: A Study of the Kumasi Metropolis, Ghana. Land 10(1):44

Gardner TA, Barlow J, Chazdon R, Ewers RM, Harvey CA, Peres CA, Sodhi NS (2009) Prospects for tropical forest biodiversity in a human-modified world. Ecol Lett 12(6):561-582

Gerlach J, Samways M, Pryke J (2013) Terrestrial invertebrates as bioindicators: an overview of available taxonomic groups. J Insect Conserv 17(4):831-850

Gómez-Cifuentes A, Munevar A, Gimenez VC, Gatti MG, Zurita GA (2017) Influence of land use on the taxonomic and functional diversity of dung beetles (Coleoptera: Scarabaeinae) in the southern Atlantic forest of Argentina. J Insect Conserv 21(1):147-156

Grodsky SM, Moorman CE, Fritts SR, Campbell JW, Sorenson CE, Bertone MA, Wigley TB (2018) Invertebrate community response to coarse woody debris removal for bioenergy production from intensively managed forests. Ecol Appl 28(1):135-148

Güneralp B, Seto KC (2013) Sub-regional assessment of China: urbanisation in biodiversity hotspots. In: Urbanization, biodiversity and ecosystem services: challenges and opportunities. Springer, Dordrecht, pp 57-63

Haeler E, Bergamini A, Blaser S, Ginzler C, Hindenlang K, Keller C, Lachat T (2021) Saproxylic species are linked to the amount and isolation of dead wood across spatial scales in a beech forest. Landsc Ecol 36(1):89-104

Ho J, Tumkaya T, Aryal S, Choi H, Claridge-Chang A (2019) Moving beyond $\mathrm{P}$ values: data analysis with estimation graphics. Nat Methods 16(7):565-566

Hodkinson ID, Jackson JK (2005) Terrestrial and aquatic invertebrates as bioindicators for environmental monitoring, with particular reference to mountain ecosystems. Environ Manag 35(5):649-666

Husch B, Beers T, Kershaw J Jr (2003) Forest mensuration, 4th edn. Willey, Hoboken

Ives CD, Lentini PE, Threlfall CG, Ikin K, Shanahan DF, Garrard GE, Kendal D (2016) Cities are hotspots for threatened species. Glob Ecol Biogeogr 25(1):117-126

Jouveau S, Toïgo M, Giffard B, Castagneyrol B, Van Halder I, Vétillard F, Jactel H (2020) Carabid activity-density increases with forest vegetation diversity at different spatial scales. Insect Conserv Divers 13(1):36-46

Keroumi AE, Naamani K, Soummane H, Dahbi A (2012) Seasonal dynamics of ant community structure in the Moroccan Argan Forest. J Insect Sci 12(1):94

Khanaposhtani MG, Kaboli M, Karami M, Etemad V (2012) Effect of habitat complexity on richness, abundance and distributional pattern of forest birds. Environ Manag 50(2):296-303

Koivula MJ (2011) Useful model organisms, indicators, or both? Ground beetles (Coleoptera, Carabidae) reflecting environmental conditions. ZooKeys 100:287

Kowarik I, Fischer LK, Kendal D (2020) Biodiversity conservation and sustainable urban development. Sustainability 12(12):4964
Latha T, Sabu TK (2019) Effects of land use change on dung beetle (Scarabaeinae) community structure in South Western Ghats. Int J Environ Agric Biotechnol 4:198-208

Lassau SA, Hochuli DF, Cassis G, Reid CA (2005) Effects of habitat complexity on forest beetle diversity: do functional groups respond consistently? Divers Distrib 11(1):73-82

Le Provost G, Badenhausser I, Le Bagousse-Pinguet Y, Clough Y, Henckel L, Violle C et al (2020) Land-use history impacts functional diversity across multiple trophic groups. Proc Natl Acad Sci 117(3):1573-1579

Lee CM, Kwon TS (2015) Response of ground arthropods to effect of urbanisation in southern Osaka, Japan. J Asia-Pac Biodivers 8(4):343-348

Leschen RA, Carlton CE (1993) Debris cloaking in endomychidae: a new species from Peru (Coleoptera). Zool J Linn Soc 109(1):35-51

Majka CG (2007) The erotylidae and endomychidae (Coleoptera: Cucujoidea) of the maritime Provinces of Canada: new records, zoogeography, and observations on beetle-fungi relationships and forest health. Zootaxa 1546(1):39-50

Mata L, Andersen AN, Morán-Ordóñez A, Hahs AK, Backstrom A, Ives CD, Lynch Y (2020) Indigenous plants promote insect biodiversity in urban greenspaces. bioRxiv

Mata L, Threlfall CG, Williams NS, Hahs AK, Malipatil M, Stork NE, Livesley SJ (2017) Conserving herbivorous and predatory insects in urban green spaces. Sci Rep 7(1):1-12

McIntyre NE (2000) Ecology of urban arthropods: a review and a call to action. Ann Entomol Soc Am 93(4):825-835

McPhearson T, Karki M, Herzog C, Santiago Fink H, Abbadie L, Kremer P, Dubbeling M (2018) Urban ecosystems and biodiversity. Urban Climate Change Research Network second assessment report on climate change in cities (ARC3-2). Cambridge University Press, Cambridge

Méndez-Rojas DM, Cultid-Medina C, Escobar F (2021) Influence of land use change on rove beetle diversity: a systematic review and global meta-analysis of a mega-diverse insect group. Ecol Ind 122:107239

Mensah CA, Andres L, Perera U, Roji A (2016) Enhancing quality of life through the lens of green spaces: a systematic review approach. Int J Wellbeing 6(1)

Mestre L, Jansson N, Ranius T (2018) Saproxylic biodiversity and decomposition rate decrease with small-scale isolation of tree hollows. Biol Cons 227:226-232

Mollot G, Pantel JH, Romanuk TN (2017) The effects of invasive species on the decline in species richness: a global meta-analysis. Adv Ecol Res 56:61-83

Muller JN, Loh S, Braggion L, Cameron S, Firn JL (2014) Diverse urban plantings managed with sufficient resource availability can increase plant productivity and arthropod diversity. Front Plant Sci 5:517

Nichols E, Larsen T, Spector S, Davis AL, Escobar F, Favila M, Network TSR (2007) Global dung beetle response to tropical forest modification and fragmentation: a quantitative literature review and meta-analysis. Biol Cons 137(1):1-19

Norton BA, Evans KL, Warren PH (2016) Urban biodiversity and landscape ecology: patterns, processes and planning. Curr Landsc Ecol Rep 1:178-192

Nyffeler M, Birkhofer K (2017) An estimated 400-800 million tons of prey are annually killed by the global spider community. Sci Nat 104(3-4):30

O'Brien MJ, Brezzi M, Schuldt A, Zhang JY, Ma K, Schmid B, Niklaus PA (2017) Tree diversity drives diversity of arthropod herbivores, but successional stage mediates detritivores. Ecol Evol 7(21):8753-8760

Oksanen J (2011) Multivariate analysis of ecological communities in R: vegan tutorial. R Package Ver 1(7):1-43 
Oliver TH, Isaac NJ, August TA, Woodcock BA, Roy DB, Bullock JM (2015) Declining resilience of ecosystem functions under biodiversity loss. Nat Commun 6(1):1-8

Owusu K, Obour PB, Asare-Baffour S (2015) Climate variability and climate change impacts on smallholder farmers in the Akuapem North District, Ghana. In: Handbook of climate change adaptation. Springer, Berlin, Heidelberg, pp 1791-1806

Parisi F, Pioli S, Lombardi F, Fravolini G, Marchetti M, Tognetti R (2018) Linking deadwood traits with saproxylic invertebrates and fungi in European forests-a review. iForest-Biogeosci for 11(3):423

Pauchard A, Aguayo M, Peña E, Urrutia R (2006) Multiple effects of urbanisation on the biodiversity of developing countries: the case of a fast-growing metropolitan area (Concepción, Chile). Biol Cons 127(3):272-281

Pielou EC (1975) Ecological diversity. Wiley, New York, p viii+165

Planchuelo G, von Der Lippe M, Kowarik I (2019) Untangling the role of urban ecosystems as habitats for endangered plant species. Landsc Urban Plan 189:320-334

Potapov AM, Dupérré N, Jochum M, Dreczko K, Klarner B, Barnes $\mathrm{AD}$, Scheu S (2020) Functional losses in ground spider communities due to habitat structure degradation under tropical land-use change. Ecology 101(3):e02957

Prieto-Benítez S, Méndez M (2011) Effects of land management on the abundance and richness of spiders (Araneae): a metaanalysis. Biol Cons 144(2):683-691

R Core Team (2019) R: a language and environment for statistical computing. R Foundation for Statistical Computing. ISBN 3-900051-07-0.

Ramos DL, Cunha WL, Evangelista J, Lira LA, Rocha MVC, Gomes PA, Togni PHB (2020) Ecosystem services provided by insects in Brazil: what do we really know? Neotrop Entomol 49:783-794

Sattler T, Duelli P, Obrist MK, Arlettaz R, Moretti M (2010) Response of arthropod species richness and functional groups to urban habitat structure and management. Landsc Ecol 25(6):941-954

Schiegg K (2000) Effects of dead wood volume and connectivity on saproxylic insect species diversity. Ecoscience 7(3):290-298

Schowalter T (2017) Arthropod diversity and functional importance in old-growth forests of North America. Forests 8(4):97

Schuldt A, Ebeling A, Kunz M, Staab M, Guimarães-Steinicke C, Bachmann D, Eisenhauer N (2019) Multiple plant diversity components drive consumer communities across ecosystems. Nat Commun 10(1):1-11

Sebek P, Vodka S, Bogusch P, Pech P, Tropek R, Weiss M, Cizek L (2016) Open-grown trees as key habitats for arthropods in temperate woodlands: the diversity, composition, and conservation value of associated communities. For Ecol Manag 380:172-181

Seibold SK (2015) Biodiversity of deadwood dependent insectseffects of forest management and prospects of conservation (Doctoral dissertation, Technische Universität München)

Seibold S, Thorn S (2018) The importance of deadwood amount for saproxylic insects and how it interacts with deadwood diversity and other habitat factors. In: Saproxylic insects. Springer, Cham, pp 607-637

Seto KC, Güneralp B, Hutyra LR (2012) Global forecasts of urban expansion to 2030 and direct impacts on biodiversity and carbon pools. Proc Natl Acad Sci 109(40):16083-16088

Shannon CE (1948) A mathematical theory of communication. Bell Syst Tech J 27(3):379-423

Shochat E, Stefanov WL, Whitehouse MEA, Faeth SH (2004) Spider diversity in the greater Phoenix area: the influence of human modificationof habitat structure and productivity. Ecol Appl $14: 268-280$

Simpson EH (1949) Measurement of diversity. Nature 163(4148):688-688

Sokal RR, Rohlf FJ (1987) Introduction to biostatistics, 2nd edn. Freeman, New York

Staab M, Schuldt A (2020) The influence of tree diversity on natural enemies - a review of the "enemies" hypothesis in forests. Curr For Rep 1-17

Štokmane M, Spungis V (2016) The influence of vegetation structure on spider species richness, diversity and community organisation in the Apšuciems calcareous fen, Latvia. Anim Biodivers Conserv 39(2):221-236

Susilo FX, Indriyati I, Hardiwinoto S (2009) Diversity and abundance of beetle (Coleoptera) functional groups in a range of land use system in Jambi, Sumatra. Biodivers J Biol Divers 10(4)

Ulyshen MD, Hanula JL (2009) Habitat associations of saproxylic beetles in the southeastern United States: a comparison of forest types, tree species and wood postures. For Ecol Manag 257(2):653-664

Underwood EC, Quinn JF (2010) Response of ants and spiders to prescribed fire in oak woodlands of California. J Insect Conserv 14(4):359-366

Vargas-Hernández JG, Zdunek-Wielgołaska J (2021) Urban green infrastructure as a tool for controlling the resilience of urban sprawl. Environ Dev Sustain 23(2):1335-1354

Wang X, Hua F, Wang L, Wilcove DS, Yu DW (2019) The biodiversity benefit of native forests and mixed-species plantations over monoculture plantations. Divers Distrib 25(11):1721-1735

Wende B, Gossner MM, Grass I, Arnstadt T, Hofrichter M, Floren A, Steffan-Dewenter I (2017) Trophic level, successional age and trait matching determine specialisation of deadwood-based interaction networks of saproxylic beetles. Proc R Soc B Biol Sci 284(1854):20170198

Wenninger EJ, Inouye RS (2008) Insect community response to plant diversity and productivity in a sagebrush-steppe ecosystem. J Arid Environ 72(1):24-33

Wiafe E (2014) Patterns of tropical tree species richness along elevational gradients of Mountain Afadjato, Ghana. Eur J for Sci 2(2): $18-23$

Zanetti NI (2016) Records of epigeal spiders in Bahia Blanca in the temperate region of Argentina. Acta Zool Mex 32(1):32-44 